\title{
Research for All, an Initiative to Promote Research in the Mauritian Society BETCHOO Nirmal Kumar ${ }^{1, a}$ \\ ${ }^{1}$ Université des Mascareignes, Beau Plan, Republic of Mauritius \\ Email address: ${ }^{a}$ betchoo@ud.ac.mu*
}

Keywords: research, involvement, community, society, Mauritius

\begin{abstract}
At a time when leaders are globally discussing of the impact of climate change on the environment, it has become a necessity for strategists to think of democratising research to enable the wider community to get opportunities to undertake and participate in research. Very often, this aspect is dismissed and the lack of citizen involvement in research leaves a majority as users of models prescribed by knowledgeable people. This paper addresses a broad concept 'Research for All' with the intention of sensitising information on allowing the community to develop, create and contribute to research in a meaningful way since bright ideas sometimes come from the community and these are commercialised by researchers. The effort of the community is usually underestimated with biased thoughts like they are not deep enough to be claimed as research but, in essence, have their contribution in society. The paper focus is on initiatives to democratise research and see how the wider community provides useful input to innovation, research and development.
\end{abstract}

\section{INTRODUCTION}

Research has been the priority of governments from all over the world as a means of developing new technology and innovation that will benefit the respective nations economically and competitively. A nation's competitiveness depends on the capacity of its industry to innovate and upgrade [1]. Advanced nations like Japan and the United States have always focused on research and this has made them make breakthrough in various spheres of life like the creation of new technologies at the industrial level with a large variety of consumer goods that have become more of a necessity today. Compared to what advanced nations have achieved in research, governments in emerging economies are now critically thinking of developing research and bringing it to further the advancement of the respective nations. In spite of its demonstrated benefits for meeting the immediate and long-term developmental goals of emerging and developing countries, the relevance of innovation for these economies is sometimes questioned [2]. It is clearly understood today that government contribution to research will be the key driver to change in the future which is already affected by environmental problems that are more dependent on the use of fossil fuels, human abuse of goods and technologies and wastage. Research has always been a government focus supported by industry captains who have collaborated in setting up research frameworks to develop a culture of research and innovation.

\section{THE RESEARCH PROBLEM}

The research problem lies in the lack of empowerment provided by the main authorities regarding the development and vulgarisation of research in the community. Public involvement in research calls for including a cross-section of stakeholders such as researchers, policymakers and civil society organisations. Including civil society representation provides a number of benefits, notably proximity to society's needs, deeper insights into research-related issues, greater legitimacy and the better dissemination of results [3].

Although, some nations in Western Europe have developed research opportunities for society members, little has been seen from people in developing countries in view of creating, developing and enabling new ideas to society. 
The research problem is supported by key questions:

1. Why is research important to the wider segment of the community?

2. What are the prejudices towards developing research at the community level?

3. What initiatives could be taken to instil research deeper in society?

4. How can society benefit from research experiences and innovation made in the community?

\section{LITERATURE REVIEW}

Research is an imperative for society and it is mainly provided from higher authorities and institutions like the government, public and private sector leaders, universities and research institutions, knowledge incubators including individuals from various spheres of society. From a general perspective, strategies are developed by government and industry people while research initiatives are undertaken at the university or tertiary education level. The nature of the businessgovernment relationship is also changing. Policymakers are being forced to reassess their models for intervention and find it increasingly difficult to understand and appropriately support industrial development [4]. The objective of undertaking research mainly relies on the factor of developing products and services that help a country achieve better knowledge and skills and equally become competitive from an economic perspective.

\section{The Central Role of Government and Industry}

Research benefits from the main contribution of government and industry. Under a mandate of five years, government is normally entrusted to develop programmes and policies that will impact on the community. The government has a major role to play in building trust and confidence amongst the public about the need and conduct of clinical trials [5]. These are in the form of strategies and intentions of action that the government will undertake through the collaboration of its stakeholders.

There is additionally the contribution of stakeholders particularly from industry who want to collaborate with the government in translating state strategies into action. The private sector is considered as the component that has the finance that could be used to develop the strategy and encourage government to fulfil its ambitions. It must recognise and take responsibility for the performance of research [6].

\section{The Influence of Public Institutions}

It would be useful to briefly describe the contribution of public institutions both in strategy and research development. Very often, the public service is viewed as a translator of actions initiated by the government. Though the perception says as such, the public service has an important role to play in the translation of strategies into action. Cohen et al (2002) reveal that a large share - almost a third of industrial R\&D projects for sample firms - made use of research findings from public research, and over a fifth made use of instruments and techniques [7]. It suffers from the lack of initiative that could be provided to public servants to enable them become deeply involved in research and innovation while this sector paradoxically has a Ministry involved in promoting research and development.

\section{A Research-led Culture}

An essential aspect of research development lies in developing a research culture. If, for example, the private sector believes that it can fund research and expect its outcomes to be of use, the public sector has a broadly limited role in this aspect. Research builds on the natural curiosity of the human person. Brew (2002 stated that education, which is based on processes of inquiry, harnesses that curiosity. We learn through research [8]. Universities and knowledge hubs come to the rescue of the different institutions highlighted above by developing research initiatives that are tailor-made for them. For example, research in sustainable development firstly meets government's 
needs to answer problems linked with addressing environmental problems. Equally, at the private sector level, it is the outcome of research from educational and research institutions that brings possible inputs to the development of new ideas.

It is of utmost importance for developing economies to think of a research-led culture. Developing countries, according to Garnera (1998) have led the way in generating approaches to ensure professional standards of behaviour through interventions such as producing guidelines and introducing essential programmes, and by producing reliable research digests to help ensure that policies are based on good evidence [9]. This initially looks like luxury for many countries assuming that the greater imperative is to think of creating jobs, addressing the impending poverty problem and devoting themselves to answering the public on politically-motivated issues.

\section{The Paradigm Shift: Bringing Research to the Community}

Abundant literature might plebiscite the importance of research at the state or strategic level but little is said of empowering the community in participating in research. Greenwood et al (1993) state that the idea is clear whereby there is little initiative from the community which is preoccupied with its petty problems and has little or nothing to do with research [10]. Another good assumption could be that government should come forward with a central idea and allow the community to participate in it. This is a plausible reason to believe how the community can provide its efforts in developing research.

The key problem does not lie here. Seen from a different perspective, communities have always been engaging themselves in developing new ideas and concepts that they have successfully or unsuccessfully applied but they have not been valued in terms of their contribution nor have they been given the chance to go deeper into research. Israel (1998) stated that partners contribute their expertise to enhance understanding of a given phenomenon and to integrate the knowledge gained with action to benefit the community involved [11]. This aspect has been left to intellectuals and researchers who have become the focal point of society as those who forwarded innovative ideas.

The literature gap might evidently lie here because a research-driven culture does not essentially depend on a few powerful people who believe that research is broadly secret and reserved for high-tech scientists and that the community basically depends on their expert skills. It is time to think of an 'all-inclusive' form of research. Lau (2008) commented that a testing concept like e-Democracy favours the use of technical tools - particularly the Internet - to allow citizens access to information; to take part in petitions, consultations, deliberation, referenda and elections; and communicate with each other to form e-communities and movements, and take part in ecampaigning and e-activism [12].

\section{THE RESEARCH BACKGROUND}

Prior to the discussion, a research background has been developed. The questions target students at the tertiary level of the Université des Mascareignes who are actively involved in undertaking academic research and were also invited to select people from the community and develop arguments that could support the central question on democratising research. As students, they firstly stated that research was the essence for their being at the University as students. Secondly, they accepted the idea of asking respondents questions on research and were particularly enthused with their eagerness to respond positively to the questions asked.

Students were divided into teams of four in a group comprising some 50 studying for the Social Sciences. They targeted some 60 respondents in urban and rural areas of Mauritius. The sampling frame was probabilistic with random samples based on age, occupation, social status and income. Since the focus of the research was on broadening a research culture in Mauritius, it addressed mainly people from middle to lower classes undertaking jobs ranging from agriculture to the services sector. 


\section{DISCUSSION}

From the discussion of the literature, the key questions are being addressed and reviewed to support the argument that research should be for all and aim at helping society to develop from and within it.

\section{Advocating Research to the Wider Community}

The first hypothesis was to consider addressing research to the wider community.

The key findings were:

\begin{tabular}{|l|l|l|}
\hline Items & Yes \% & No \% \\
\hline a) Members of society must have research knowledge. & 56 & 44 \\
\hline b) Research should be collaborative. & 67 & 33 \\
\hline c) Personal research should be encouraged. & 58 & 42 \\
\hline $\begin{array}{l}\text { d) Research should involve a wide range of participants from } \\
\text { society. }\end{array}$ & 76 & 24 \\
\hline
\end{tabular}

Members were keen to have some understanding of research. There was a high consensus regarding the need to bring research within the environment of society. Though research was viewed as essentially technical, it was considered to be important. There were areas that demanded technical knowledge namely construction, health concerns, etc.

Collaborative research was highly regarded. For example, in the construction sector, masons are the users of concrete and construction blocks. Their suggestions are helpful. Their ideas in the mix percentage of concrete but gluing materials was raised.

Personal research was mainly supported by intellectuals in the community. For example, coming forward with new ideas were usually assignments done at the university level with little application. This idea was forwarded so as to deepen research in the same area but also disclose it at the national level.

The involvement of society at large was highly viewed by the respondents as they had the perception that it was exclusively for a happy few. There were always doubts and preconceived ideas about not getting the community participate in research. In the fishing industry, fishermen suggested the Ministry of Fisheries, Mauritius, on the variety of fish to breed. These are the grounds for the call to integrate science and society [13].

\section{Prejudices towards Developing Research at the Community Level}

The second hypothesis was to assess the prejudices that the general community might have against research.

The following findings were recorded.

\begin{tabular}{|l|l|l|}
\hline Items & Yes \% & No \% \\
\hline e) Research is essentially academic and of high level. & 75 & 25 \\
\hline f) Research is not meant for the public. & 92 & 8 \\
\hline $\begin{array}{l}\text { g) Research needs to be supported as people are inadequately } \\
\text { qualified from the community. }\end{array}$ & 82 & 18 \\
\hline h) The community does not undertake essential research. & 64 & 36 \\
\hline i) Research in the community is simple and practical. & 70 & 30 \\
\hline
\end{tabular}

The main prejudice against research in the community is that it is perceived as academic and demanding, conditions that generally could not be fulfilled by the community. The high level of performance demanded from research was a deterrent. 
A simple statement as research is not meant for the public drove a very high percentage of respondents thinking that it was only meant for academics and experienced researchers.

An important argument was that research should get the support of qualified researchers since the community is in general poorly qualified and equipped to do research. This was again highly rated by the respondents ( $82 \%$ against $18 \%)$.

The community was under the impression that it could not undertake essential research. It could better at doing basic and practical research which was also coupled to Item 4.

From a generalised perspective, prejudices against involving the community in research were quite high and this could be viewed as a deterrent for community engagement in the process of research democratisation in Mauritius. This is supported by the Multimotive model (2009) stating that people's reactions to perceiving that they are inadequately valued and accepted by others involve a complex, interactive, dynamic system of cognitive, emotional, motivational, and behavioural responses [14].

\section{Initiatives to Better Instil Research in Society}

The third hypothesis focused on initiatives to better instil research in the Mauritian society. Since a long time, government has been favouring a research culture but this has not been clearly developed at the societal level. Certain key issues ae addressed in the table below.

\begin{tabular}{|l|l|l|}
\hline Items & Yes \% & No \% \\
\hline j) The public must be invited to participate in research. & 81 & 19 \\
\hline $\begin{array}{l}\text { k) Research initiatives should be launched since primary } \\
\text { education. }\end{array}$ & 66 & 34 \\
\hline 1) Government must be supportive in promoting research. & 70 & 30 \\
\hline $\begin{array}{l}\text { m) Research ideas from the community must be welcome and } \\
\text { developed. }\end{array}$ & 82 & 18 \\
\hline $\begin{array}{l}\text { n) Encouragement to undertake research must be promulgated at } \\
\text { the community level. }\end{array}$ & 74 & 26 \\
\hline
\end{tabular}

Community members that formed part of the respondents highly believed that the public must be invited to participate in research. Citizen participation is a process which provides private individuals an opportunity to influence public decisions and has long been a component of the democratic decision-making process [15].

This was so far selective and targeted to professionals only.

Research initiatives should be developed since primary school level. The question here was whether this could trigger further research during schooling years and whether this could be pursued later on.

Respondents confirmed that the government had its part to play in developing research initiatives. The public was already responding to government campaigns on tropical diseases and could hence expect the public to participate more constructively in research.

Welcoming research ideas was important $(82 \%$ in favour) while this was generally developed by different Ministries within the government. In line with this, community members asked for encouragement that should be provided to them to initiate research for the benefit of society. 


\section{Society benefiting from research experiences and innovation from the community}

The final hypothesis tested the benefit that community would provide and benefit from research experiences and innovation. The questions asked covered the following items.

\begin{tabular}{|l|l|l|}
\hline Items & Yes \% & No \% \\
\hline $\begin{array}{l}\text { p) Community involvement in research would be proactive in } \\
\text { addressing social issues. }\end{array}$ & 66 & 34 \\
\hline $\begin{array}{l}\text { q) There would be higher level of sensitisation of the public in } \\
\text { issues affecting them. }\end{array}$ & 71 & 29 \\
\hline $\begin{array}{l}\text { r) Innovation would make the community have access to new } \\
\text { benefits. }\end{array}$ & 76 & 24 \\
\hline s) A culture of research would develop a competitive nation. & 70 & 30 \\
\hline t) Research would be democratised and made all inclusive. & 65 & 35 \\
\hline
\end{tabular}

Respondents stated that an involvement of the community in research would make the public be more proactive to social issues. Active citizenship means people getting involved in their local communities and democracy at all levels, from towns to cities to nationwide activity. Such citizenship is one of the most important steps towards healthy societies especially in new democracies like Hungary [16].

These could be in the form of creating positive attitudes with regards to environmental changes, global warming, sustainable development, etc.

Public sensitisation would be greater. This question supported the first argument where proactivity and sensitisation would go in parallel provided that the community would be involved in research. In India, there are efforts made by the government towards the promotion of innovation for entrepreneurship development and sustainable growth that is poised to make a big leap towards innovation-led growth [17].

Innovation would make the community have access to new benefits. For example, the possibility of using solar panels could enable the public become partially self-dependent in using electricity. Equally, the collection of rain water could develop water stock for domestic purposesnot for drinking-in times of severe drought.

A broader perspective was that research culture could sustain the creation of a competitive nation that contributes to the development of Mauritius as an intelligent island.

To sum up the hypothesis, research could become democratised and include all the actors of society. This could also better position Mauritius as a hub with emphasis on its core resources, namely human resources.

\section{Mean Values, Standard Deviation and variance}

The mean values for all the four hypothesis in support of research for all were assessed as follows. All items were based on YES statements made by respondents. NO statements were not accounted for.

\begin{tabular}{|c|c|c|}
\hline Items & $\begin{array}{l}\text { Mean } \\
\text { Values }\end{array}$ & $\begin{array}{l}\text { Deviation } \\
\text { from Mean }\end{array}$ \\
\hline 1. Advocating Research to the Wider Community & 64.3 & -7.0 \\
\hline $\begin{array}{l}\text { 2. Prejudices towards Developing Research at the Community } \\
\text { Level }\end{array}$ & 76.6 & 5.3 \\
\hline 3. Initiatives to Better Instil Research in Society & 74.6 & 3.3 \\
\hline $\begin{array}{l}\text { 4. Society Benefiting from Research Experiences and } \\
\text { Innovation from the Community }\end{array}$ & 69.6 & -1.7 \\
\hline Mean Value & 71.3 & $\mathrm{~N}=4$ \\
\hline Standard Deviation & 5.5 & Variance $=30$ \\
\hline
\end{tabular}


The four hypotheses were plotted with their mean values to illustrate how they could vary from the average mean value. The chart (Figure 1) illustrates the deviations from the mean value and illustrate a high level of positivity from two hypotheses (2 and 3 ). There were some differences between hypotheses 1 and 4 illustrating some slight variance from the mean depending on how they responded to the questions.

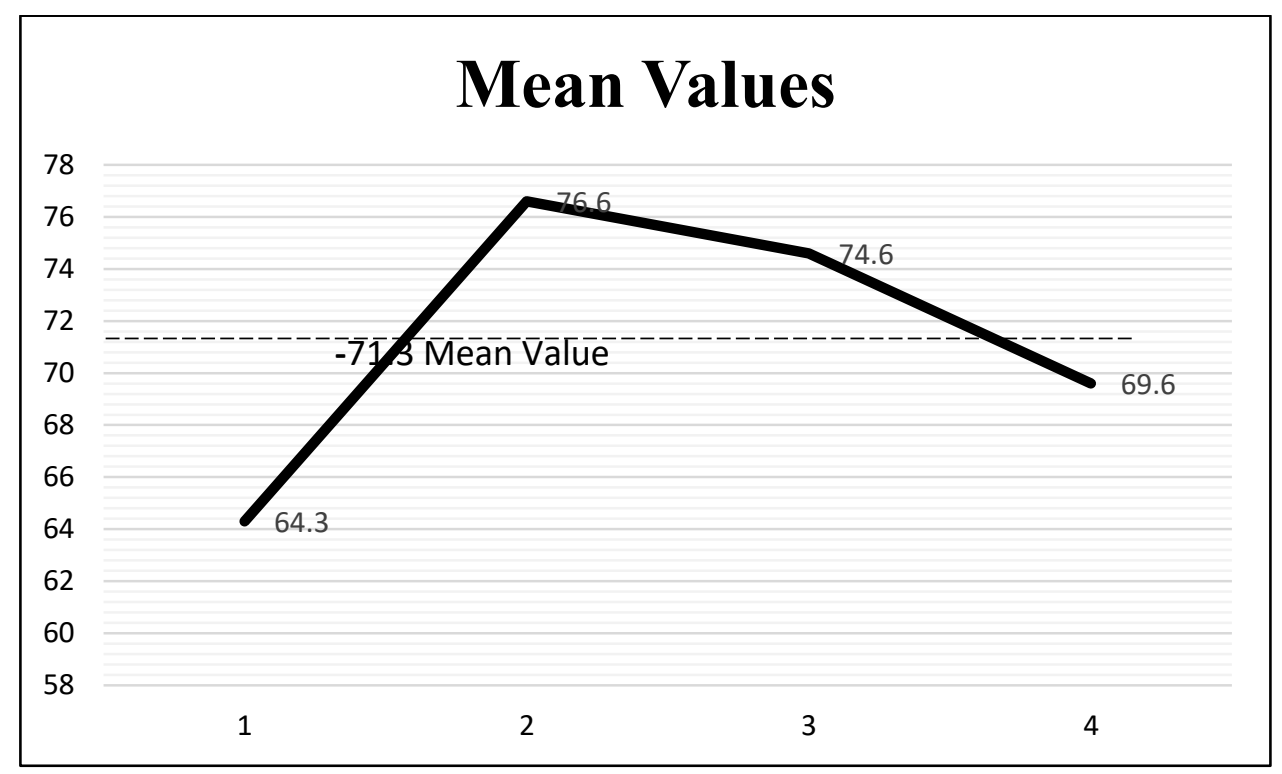

Figure 1: Mean values of hypotheses and their dispersion from the Average Mean.

\section{CONCLUSION}

The observations proved that it was generally more difficult to gain community involvement in stating that they should be part and parcel of research undertaken at the national level. There were hindrances among the target audience. Equally, it was seen that community members could not adequately assess how research done by them would have a positive impact on society. These were understated by hindrances that the community could have from research with the feeling that it was the affair of researchers and academics. There was a tendency that was much favourable to create initiatives for research for the community.

Certain examples are clear here. For example, contributions from society members are required in policies debated by the government like the preparation of a budget or reporting corruption to the State on a voluntary basis. The outcomes have not been deeply gauged. However, reactions from the public like protests against Summer Time in Mauritius to save energy resulted in government's withdrawal of the policy twice. There still remain several areas to get public involvement not in advocating views but more in engaging itself in participative research that benefits society and the country equally. Increasingly, public involvement is a requirement of applying for research funding and used by commissioners as an indicator of the quality of a research application [18]. It is based on the view that members of the public can bring knowledge and experience of a particular condition or service relevant to the research topic, a public perspective and views about the best ways to involve other users and carers in research [19]. In Mauritius, it has been noted that people are not interested in policy-making in some cases. This is a serious handicap and no effort should be spared towards restoring their trust in institutions and involving them in decision-making [20]. This is what this piece of research focusing on democratising it in Mauritius could make sense. 


\section{References}

[1] Porter, M. (1990). The Competitive Advantage of Nations. Harvard Business Review.

[2] OECD. (2012). Innovation for Development. Organisation for Economic Cooperation and Development.

[3] European Economic Science Community. (2015). Bridging the gap between research and society. Retrieved from http://www.eesc.europa.eu

[4] International Finamcial Management Research (2015). Industry and Government. University of Cambridge.

[5] Bhatt, A. (2012). Government's role in shaping public perceptions about clinical research. Perspectives in Clinical Research.

[6] Government Procurement Office (2012). The Private Sector's Role in the Scientific Enterprise. Retrieved from gpo: http://www.gpo.gov/fdsys/pkg/GPO-CPRT-105hprt105b/html/prsecrol.html.

[7] Cohen, W.M., R.R. Nelson and J.P. Walsh (2002), "Links and impacts: the influence of public research on industrial R\&D", Management Science, 48, 1-23.

[8] Brew, A. (2002). Enhancing the quality of learning through research-led. HERDSA, 1-11.

[9] Garnera, P. (1998). Implementing research findings in developing countries. BMJ Publishing Group Ltd. Retrieved from http://pages.uoregon.edu/rgp/PPPM613/class10theory.htm

[10] Greenwood, W. F., Davydd J., and Morten L. (1993). Participatory Action Research as a Process and as a Goal. SAGE Open, vol. 46 no. 2 175-192.

[11] Israel, A. J. (1998). Review Of Community-Based Research: Assessing Partnership Approaches to Improve Public Health. Annual Review of Public Health, DOI: 10.1146.

[12] Ibid 3.

[13] Lau, T. (2008). EDemocracy research requires all-inclusive approach, conference told. European Science Foundation.

[14] Leary, L. S. (2009 doi: 10.1037/a0015250). Reactions to Discrimination, Stigmatization, Ostracism, and Other Forms of Interpersonal Rejection. US National Library of Medicine .

[15] Parker, B. (2003) Planning Analysis: The Theory of Citizen Participation,

[16] Nosko, A. \& Széger, K. (2013) Active Citizenship Can Change Your Country for the Better, Open Society Foundation.

[17] Abhyankar, P. (2014) The Government of India's Role in Promoting Innovation through Policy Initiatives for Entrepreneurship Development, Technology, innovation and Management Review.

[18] Faulkner A and Morris B. (2003) Expert paper: User involvement in forensic mental health research and development. www.nfmhp.org.uk - see Expert Paper Series.

[19] Hanley B. (2005) Research as empowerment? Report of a series of seminars organised by the Toronto Group. Joseph Rowntree Foundation. www.jrf.org.uk.

[20] Elahee, K. (2009) Maurice Ile Durable Project Analysis and Synthesis Report, White Paper, University of Mauritius. 